\title{
Exploring the potential of fungal manganese-containing lipoxygenase for pitch control and pulp delignification
}

\author{
Gisela Marques $^{\mathrm{a}}$, Setefilla Molina ${ }^{\mathrm{a}}$, Esteban D. Babot ${ }^{\mathrm{a}}$, Henrik Lund ${ }^{\mathrm{b}}$, José C.del Río ${ }^{\mathrm{a}}$, Ana Gutiérrez ${ }^{\mathrm{a}, *}$ \\ ${ }^{a}$ Instituto de Recursos Naturales y Agrobiología de Sevilla, CSIC, P.O. Box 1052, E-41080 Seville, Spain \\ ${ }^{\mathrm{b}}$ Novozymes A/S, Krogshoejvej 36, DK-2880 Bagsvaerd, Denmark
}

\section{A R T I C L E I N F O}

\section{Article history:}

Received 27 May 2010

Received in revised form 29 August 2010

Accepted 30 August 2010

Available online 22 September 2010

\section{Keywords:}

Fungal lipoxygenase

Pitch deposits

Lignin removal

Lipid peroxidation

\begin{abstract}
A B S T R A C T
The potential of the lipoxygenase from Gaeumannomyces graminis to remove lipophilic extractives from eucalypt and flax pulps was investigated. Pulp treatments were performed with the lipoxygenase both in the presence and absence of linoleic acid, and were followed by a peroxide bleaching stage. The main lipophilic extractives from eucalypt pulp such as conjugated and free sterols decreased up to $40 \%$ and $7 \%$, respectively, by the lipoxygenase treatment in the presence of linoleic acid. Different degradation patterns were observed among the lipophilic compounds present in flax pulp, although a high removal of all the extractives classes, including alkanes (21-55\%), fatty alcohols (42-61\%), and free (16-55\%) and glycosylated (45-71\%) sterols, was attained in all the lipoxygenase treatments. Reactions of the lipoxygenase with model lipid mixtures were carried out to better understand the degradation patterns observed in pulps. Finally, pulp delignification by the lipoxygenase treatments was also evaluated.
\end{abstract}

(c) 2010 Elsevier Ltd. All rights reserved.

\section{Introduction}

The non-polar extractable fraction from wood and nonwood fibers, commonly referred to as lipophilic extractives, includes fatty and resin acids, fatty alcohols, alkanes, sterols, sterol esters and triglycerides. These lipophilic compounds are the precursors of the so-called pitch deposits within the pulp and paper manufacturing processes (Back and Allen, 2000). Pitch deposition results in low quality pulp, and can cause the shutdown of pulp mill operations. Specific issues related to pulps with high extractives content include runnability problems, spots and holes in the paper, and sheet breaks.

In addition to physicochemical methods, biological methods including both enzymes and microorganisms (Gutiérrez et al., 2001a, 2009), have been investigated to control pitch problems in the pulp and paper industry. Lipases, which hydrolyze triglycerides, are applied with success in softwood (mainly pine) mechanical pulping at mill scale (Fujita et al., 1992) and find widespread use nowadays. However, pitch problems in most of the chemical and mechanical processes using other raw materials have not yet been solved. Other compounds, such as free and esterified sterols, resin acids, fatty alcohols and alkanes, are responsible for pitch problems in these processes (Gutiérrez et al., 2009). In addition to lipases, the use of sterol esterases has also been suggested (Barfoed, 2000) because sterol esters are often at the origin of pitch

\footnotetext{
* Corresponding author. Tel.: +34 95 4624711; fax: +34 954624002.

E-mail address: anagu@irnase.csic.es (A. Gutiérrez).
}

deposits owing to their high tackiness and resistance to kraft cooking. However, free sterols released by the action of these esterases are as problematic as sterol esters.

On the other hand, the modification of some lipophilic extractives by the use of oxidative enzymes such as laccases has been reported (Buchert et al., 2002; Molina et al., 2008; Zhang et al., 2005). Moreover, the use of laccases in the presence of redox mediators that have been extensively studied for pulp delignification (Bourbonnais and Paice, 1990; Call, 1994; Camarero et al., 2004; Fillat et al., 2010; Moldes et al., 2008) has recently been described for the removal of the lipophilic extractives responsible for pitch deposition (Gutiérrez et al., 2006a,b, 2007; Molina et al., 2008; Valls et al., 2009).

In addition to laccases, other oxidative enzymes, such as soybean lipoxygenases have been tested for the degradation of extractives in softwood thermo-mechanical pulp (Zhang et al., 2007). Earlier work had also suggested the use of lipoxygenases to reduce model wood "pitch" mixtures in pulp and paper (Borch et al., 2003). Lipoxygenases are dioxygenases which catalyze the oxidation of polyunsaturated fatty acids to hydroperoxides. Despite extensive studies on this group of enzymes (Brash, 1999; Hamberg et al., 1998; Prigge et al., 1997; Su and Oliw, 1998), there is a lack of utilization of these natural abundant enzymes in industrial processing. The specific activity of lipoxygenases to degrade linoleic acid leads to a potential application in papermaking processes to degrade wood extractives that have adverse effects on pulp and paper properties. In the present work, we study the capability of the lipoxygenase from the fungus Gaeumannomyces graminis to 
remove lipophilic extractives from hardwood (eucalypt) and nonwoody (flax) pulps. This enzyme is a manganese-containing lipoxygenase with several exceptional features different from other lipoxygenases (Hamberg et al., 1998; Su and Oliw, 1998). It has a broad $\mathrm{pH}$ range (being active between $\mathrm{pH} 5$ and 11), and good heat stability (being active at temperatures up to $60^{\circ} \mathrm{C}$ ) (Su and Oliw, 1998) which confer great potential of use under mill process conditions. Since the oxidation of polyunsaturated fatty acids by lipoxygenase leads to the formation of reactive fatty acid hydroperoxides and lipid radicals (Prigge et al., 1997) that can co-oxidize lignin in addition to lipids (Kapich et al., 2010), delignification of this pulp mediated by lipoxygenase treatment in the presence of linoleic acid was also investigated.

\section{Methods}

\subsection{Pulp samples}

Unbleached kraft pulp from eucalypt (Eucalyptus globulus) wood, with 44\% ISO brightness and 13.5 kappa number was obtained from ENCE (Pontevedra, Spain). Unbleached soda/anthraquinone (AQ) pulp from flax (Linum usitatissimum) with 34\% ISO brightness and 11 kappa number was provided by CELESA (Tortosa, Spain).

\subsection{Model lipids}

Linoleic acid, cholesteryl linoleate, nonacosane and octacosanol (from Sigma-Aldrich) and sitosterol (from Calbiochem) were used.

\subsection{Lipoxygenase}

The G. graminis lipoxygenase (GLOX) preparation was provided by Novozymes (Bagsvaerd, Denmark). GLOX is a recombinant enzyme, and the preparation used had a purity of $50 \%$ based on the sodium dodecyl sulfate gel including very low levels of protease, amylase and lipase activities. The other proteins present derived from GLOX proteolysis. GLOX activity was 130,000 units per mg, where one unit will cause an absorbance increase at $234 \mathrm{~nm}$ of 0.001 units per min, at $\mathrm{pH} 7.0$ and $30^{\circ} \mathrm{C}$, when linoleic acid is used as substrate in a reaction volume of $1.0 \mathrm{ml}$ (light path $1 \mathrm{~cm}$ ).

\subsection{Enzymatic treatments of paper pulps}

Pulp treatments with GLOX (10 mg/g eucalypt pulp and $20 \mathrm{mg} /$ $\mathrm{g}$ flax pulp) were carried out using $5 \mathrm{~g}$ pulp (dry weight) at $1 \%$ consistency (w:w) in $100 \mathrm{mM}$ monosodium phosphate (pH 7), $30^{\circ} \mathrm{C}$, with oxygen bubbling, in a thermostatic shaker at $170 \mathrm{rev} / \mathrm{min}$ for $4 \mathrm{~h}$. Pulp treatments were performed in the presence and absence of linoleic acid ( $0.1 \mathrm{mg} / \mathrm{g}$ pulp). In a subsequent step, pulps at $5 \%$ consistency $(\mathrm{w}: \mathrm{w})$ were submitted to a bleaching stage using $3 \%$ (w:w) $\mathrm{H}_{2} \mathrm{O}_{2}$ and $1.5 \%$ (w:w) $\mathrm{NaOH}$, both referred to pulp dry weight, at $90{ }^{\circ} \mathrm{C}$ for $2 \mathrm{~h}$. Controls without GLOX were performed. Treated pulp samples were Soxhlet extracted with acetone $(8 \mathrm{~h})$ and the extracts were evaporated to dryness and redissolved in chloroform for gas chromatography/mass spectrometry (GC-MS) and GC analyses. When required, bis(trimethylsilyl)trifluoroacetamide (BSTFA, from Supelco) in the presence of pyridine was used to prepare trimethylsilyl derivatives.

\subsection{Enzymatic reactions with model lipids}

Enzymatic reactions with mixtures of model compounds listed in Section $2.2(1 \mathrm{mg})$ were performed using GLOX $(0.1 \mathrm{mg} / \mathrm{mg}$ lipid), and Tween 20 as dispersant ( $1 \% \mathrm{v} / \mathrm{v})$ in $100 \mathrm{mM}$ monosodium phosphate ( $\mathrm{pH} \mathrm{7),30}{ }^{\circ} \mathrm{C}$, with oxygen bubbling, in a thermostatic shaker at $100 \mathrm{rev} / \mathrm{min}$ for $2 \mathrm{~h}$. Controls without GLOX were performed.

After the enzymatic treatments, the lipid dispersions were immediately evaporated, and the reaction products recovered with chloroform:methanol (1:1), dried and redissolved in chloroform for GC and GC-MS analyses. When required, BSTFA in the presence of pyridine was used to prepare trimethylsilyl derivatives.

\subsection{GC and GC-MS analyses of lipids}

The GC analyses of lipids from both the enzymatic treatments of pulps and enzymatic reactions with model compounds were performed in an Agilent $6890 \mathrm{~N}$ Network GC system using a short fused-silica DB-5HT capillary column $(5 \mathrm{~m} \times 0.25 \mathrm{~mm}$ internal diameter, $0.1 \mu \mathrm{m}$ film thickness) from J\&W Scientific, enabling simultaneous elution of the different lipid classes. The temperature program was started at $100{ }^{\circ} \mathrm{C}$ with $1 \mathrm{~min}$ hold, and then raised to $350{ }^{\circ} \mathrm{C}$ at $15^{\circ} \mathrm{C} / \mathrm{min}$, and held for $3 \mathrm{~min}$. The injector and flameionization detector (FID) temperatures were set at 300 and $350{ }^{\circ} \mathrm{C}$, respectively. Helium was used as carrier gas, and the injection was performed in splitless mode (Gutiérrez et al., 1998). Peaks were quantified by area, and data from replicates were averaged. In all cases the standard deviations were below $7 \%$ of the mean values.

The GC-MS analyses were performed with a Varian 3800 chromatograph coupled to an ion-trap detector (Varian 4000) using a medium-length $(12 \mathrm{~m})$ capillary column of the same characteristics described above for GC/FID. The oven was heated from 120 ( $1 \mathrm{~min}$ ) to $380^{\circ} \mathrm{C}$ at $10^{\circ} \mathrm{C} / \mathrm{min}$, and held for $5 \mathrm{~min}$. In all the GC-MS analyses, the transfer line was kept at $300^{\circ} \mathrm{C}$, the injector was programmed from $120(0.1 \mathrm{~min})$ to $380^{\circ} \mathrm{C}$ at $200{ }^{\circ} \mathrm{C} / \mathrm{min}$ and held until the end of the analysis, and helium was used as carrier gas at a rate of $2 \mathrm{ml} / \mathrm{min}$. Compounds were identified by mass fragmentography, and by comparing their mass spectra with those of the Wiley and NIST libraries and standards.

\subsection{Pulp evaluation}

Pulp brightness, kappa number and intrinsic viscosity were analyzed following ISO 3688:1999, ISO 302:1981 and ISO 5351/1:1981 standard methods, respectively (International Organisation for Standardization Documentation and Information (ISO), 2003). Data from replicates were averaged. In all cases the standard deviations were below $2 \%$ of the mean values.

\section{Results and discussion}

\subsection{Composition of lipophilic extractives in eucalypt and flax pulps}

The lipophilic extractives from eucalypt and flax pulps were analyzed by GC and GC-MS. The main lipophilic compounds present in eucalypt pulp included sterols (predominantly sitosterol) in free and conjugated form, both as glycosides and esters, as well as fatty acids, mainly palmitic acid. The detailed composition of lipophilic extractives from eucalypt pulp has been published elsewhere (Gutiérrez and del Río, 2001; Gutiérrez et al., 2001b). Among these compounds, free and esterified sterols have been reported to be the main responsible for pitch deposition during the manufacturing of eucalypt pulp (Gutiérrez et al., 2009). On the other hand, fatty alcohols including hexacosanol, octacosanol, and triacontanol, free sterols with sitosterol predominating, and fatty acids, predominantly palmitic acid, linoleic acid, oleic acid and stearic acid were the main lipophilic extractives identified in flax pulp. Minor amounts of alkanes such as nonacosane and sterol 
glycosides were also present. The detailed characterization of lipophilic extractives from flax pulp has already been reported (Marques et al., 2010). Fatty alcohols and alkanes have been shown as the main responsible for pitch problems during manufacturing of nonwoody soda pulps (Gutiérrez and del Río, 2005).

From the analysis of pulp extractives it would not be expected to see a significant change in their total content after treatment with GLOX given that the amount of extractives with the 1-cis,4cis-pentadiene structure (i.e. linoleic acid) is quite scarce. Still it was chosen to pursue testing of GLOX on both pulps and model substrates since other studies (Gutiérrez et al., 1999) had shown the presence of linoleic acid esterified with sitosterol as the main sterol ester among eucalypt extractives and, at the same time, other studies had surprisingly described an ability of lipoxygenase to significantly impact other components in unbleached eucalypt kraft pulp (Borch et al., 2003).

\subsection{Removal of pulp lipophilic extractives by lipoxygenase treatment}

The eucalypt and flax pulps were treated with the lipoxygenase from G. graminis (GLOX) to evaluate the potential of this enzyme to remove lipophilic extractives from these pulps. Additional assays adding linoleic acid to the enzymatic reactions were also performed to study the mediating effect of peroxidation products on the lipid removal. After the enzymatic treatments, the pulps were subsequently submitted to a hydrogen peroxide bleaching stage, which is a common stage in the bleaching of these alkaline pulps. The composition of the lipophilic extractives in pulps after the treatment with GLOX was analyzed by GC and GC-MS and compared with that of the control pulp treated under the same conditions but without enzyme addition.

\subsubsection{Eucalypt pulp treatments}

Table 1 shows the percentage of degradation of the main eucalypt pulp extractives after the enzymatic treatment with GLOX. GLOX treatment produced a removal of $20 \%$ and $22 \%$ of the sterol esters and sterol glycosides, respectively, but the amount of free sterols remained unchanged. A similar lack of degradation of free sterols was also observed after TMP pulp treatment with soybean lipoxygenase (Zhang et al., 2007).

When the GLOX treatments were performed in the presence of linoleic acid, a higher decrease of sterol esters and glycosides (up to $29 \%$ and $24 \%$, respectively) was observed but the content of free sterols was not modified. On the other hand, in the GLOX treatments followed by a hydrogen peroxide stage, the addition of linoleic acid to the enzymatic reaction caused a higher removal of sterol esters (from 27\% to $40 \%$ ) and sterol glycosides (from $20 \%$ to $39 \%$ ). It appears that the effect of the lipoxygenase treatment can extend well beyond the primary substrates of the enzyme via the fatty acid hydroperoxides. A slight decrease of free sterols (from $0 \%$ to $7 \%$ ) was also observed. Higher reductions in the content of free and conjugated sterols have been reported in treatments of eucalypt pulp with laccases in the presence of redox mediators (Gutiérrez et al., 2006a,b, 2007).

Table 1

Removal (percentage of reduction) of the main lipophilic extractives in eucalypt pulp after treatment with the G. graminis lipoxygenase (GLOX) in the absence and presence of linoleic acid (LA), without and with a subsequent $\mathrm{H}_{2} \mathrm{O}_{2}$ stage (P).

\begin{tabular}{llllll}
\hline & \multicolumn{2}{l}{ Without $\mathrm{H}_{2} \mathrm{O}_{2}$} & & With $\mathrm{H}_{2} \mathrm{O}_{2}$ & \\
\cline { 2 - 3 } \cline { 5 - 6 } & $\mathrm{GLOX}$ & GLOX/LA & & GLOX-P & GLOX/LA-P \\
\hline Free sterols & 0 & 0 & & 0 & 7 \\
Sterol glycosides & 22 & 24 & & 20 & 39 \\
Sterol esters & 20 & 29 & & 27 & 40 \\
\hline
\end{tabular}

To get further insight into these enzymatic reactions, GLOX reactions with model compounds (Fig. 1) representative for the main lipophilic extractives in eucalypt pulp, including free and esterified sterols (sitosterol and cholesteryl linoleate, respectively), and free fatty acids (linoleic acid) were carried out. The reactivity of the different lipids was studied by GC and GC-MS. The content of cholesteryl linoleate decreased about $20 \%$ while the content of free sitosterol remained unchanged by the GLOX treatment. In addition, linoleic acid was completely degraded, as expected. When the GLOX reactions were performed with a mixture of the three model compounds, reductions of $83 \%$ and $25 \%$ of cholesteryl linoleate and sitosterol, respectively, were observed in the reactions of lipoxygenase, suggesting that peroxidation reactions could mediate the co-oxidation of these model lipids. The co-oxidation of sitosterol observed in the reaction of GLOX with the model mixture was not observed in the eucalypt pulp treatment. One potential reason for the limited effect of the pulp treatment on the free sterols may be the predominant localization of these compounds inside the pulp elements (Speranza et al., 2002).

In the reaction of lipoxygenase with mixtures of the three model lipids, oxidative derivatives of cholesteryl linoleate and free sitosterol were observed. The reaction products of cholesteryl linoleate were cholesta-3,5-dien-7-one and the cholesteryl ester core aldehyde. Oxidized derivatives of free sitosterol, namely $7 \beta-$ hydroxysitosterol (and traces of $7 \alpha$-hydroxysitosterol) and 7-ketositosterol were also observed. The chemical structures of the main oxidation products identified are shown in Fig. 2. These oxidized derivatives were also identified in the enzymatic reactions of these model lipids with laccase in the presence of 1-hydroxybenzotriazole (HBT) as redox mediator (Molina et al., 2008).

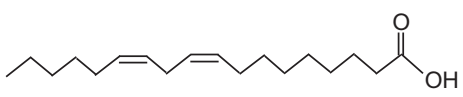

a<smiles>CCC(CCC(C)C1CCC2C3CC=C4CC(O)CCC4(C)C3CCC12C)C(C)C</smiles><smiles>CCCCCC=CC=CCCCCCCC(=O)OC1CCC2(C)C(=CCC3C2CCC2(C)C(C(C)CCCC(C)C)CCC32)C1</smiles>

C

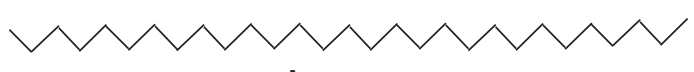

d

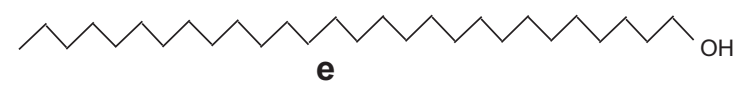

Fig. 1. Chemical structures of the model compounds representative for main paper pulp lipophilic extractives used in the enzymatic reactions: (a) linoleic acid; (b) sitosterol; (c) cholesteryl linoleate; (d) nonacosane and (e) octacosanol. 


\section{Sitosterol oxidation products:}
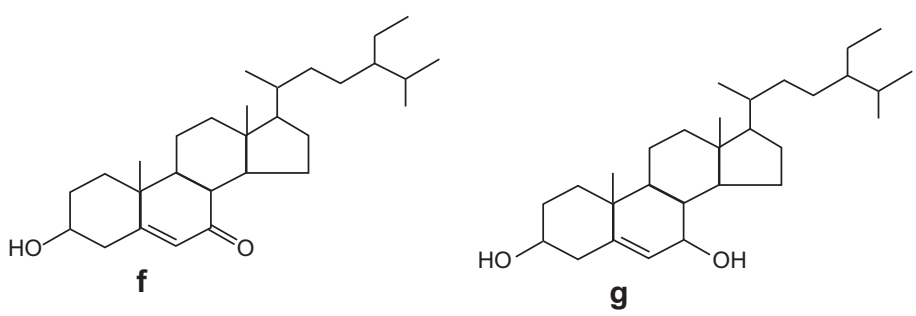

\section{Cholesteryl linoleate oxidation products:}

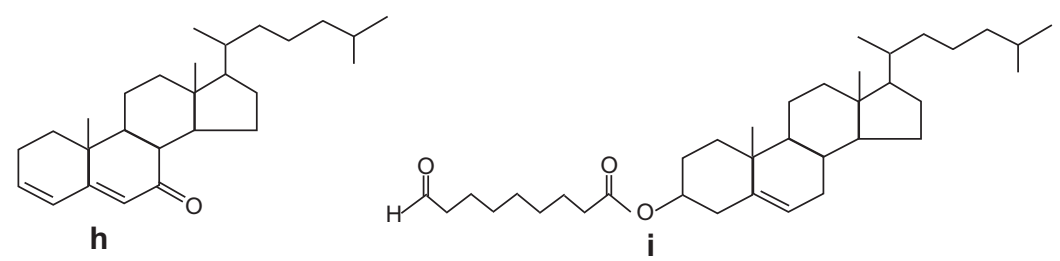

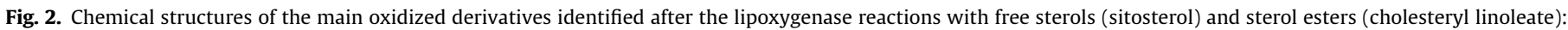
(f) 7-ketositosterol; (g) 7 $\beta$-hydroxysitosterol; (h) cholesta-3,5-dien-7-one and (i) cholesteryl 9-oxononanoate.

\subsubsection{Flax pulp treatments}

The percentage of removal of the lipophilic extractives from flax pulp by the GLOX treatment is shown in Table 2. All these lipophilic compounds decreased significantly in the several GLOX treatments. A high removal of alkanes (up to 48\%), fatty alcohols (upto 61\%) and sterol glycosides (up to 65\%) was observed. Surprisingly, the content of free sterols in flax pulp decreased up to $55 \%$ after the GLOX treatments, contrasting with the lack of removal in eucalypt pulp where no effect on free sterols was observed. This can be due to a different distribution of sterols in both pulps. The sterols present in flax are likely distributed throughout the surface layers of the fibers alongside the other lipophilic components (Morrison and Akin, 2001) and may be partially co-solubilized with them, following the reaction with the lipoxygenase on the cis-cispentadiene structures present in flax pulp.

The above reductions in the lipophilic extractives contents by the GLOX treatment are similar to those reported for laccase treatments of flax pulp in the presence of HBT (Gutiérrez et al., 2006b). The GLOX treatment has the advantage that no mediator was added.

The addition of linoleic acid to these enzymatic reactions caused different effects upon the different lipophilic compounds. A higher removal of alkanes was observed by the addition of linoleic acid whereas the contrary happened with fatty alcohols, free sterols

Table 2

Removal (percentage of the reduction) of the main lipophilic extractives in flax pulp after treatment with the G. graminis lipoxygenase (GLOX) in the absence and presence of linoleic acid (LA) without and with a subsequent $\mathrm{H}_{2} \mathrm{O}_{2}$ stage (P).

\begin{tabular}{llllll}
\hline & \multicolumn{2}{l}{ Without $\mathrm{H}_{2} \mathrm{O}_{2}$} & & \multicolumn{2}{l}{ With $\mathrm{H}_{2} \mathrm{O}_{2}$} \\
\cline { 2 - 3 } \cline { 5 - 6 } & $\mathrm{GLOX}$ & GLOX/LA & & GLOX-P & GLOX/LA-P \\
\hline Alkane (C27) & 26 & 39 & & 21 & 46 \\
Alkane (C29) & 48 & 54 & & 35 & 55 \\
Fatty alcohol (C26) & 48 & 44 & & 45 & 50 \\
Fatty alcohol (C28) & 55 & 44 & & 42 & 49 \\
Fatty alcohol (C30) & 61 & 43 & & 52 & 52 \\
Free sterols & 55 & 30 & & 16 & 34 \\
Sterol glycosides & 65 & 51 & & 45 & 71 \\
\hline
\end{tabular}

and sterol glycosides. In the GLOX treatments of flax pulp followed by a hydrogen peroxide stage, the addition of linoleic caused an increase in the removal of all the lipophilic extractives.

Reactions of GLOX with mixtures of four model compounds (Fig. 1) representative for the main lipophilic extractives in flax pulp, including alkanes (nonacosane), fatty alcohols (octacosanol), free sterols (sitosterol), and free fatty acids (linoleic acid) were also carried out. The GC and GC-MS analyses showed reductions of $100 \%, 51 \%, 65 \%$ and $55 \%$ of linoleic acid, nonacosane, octacosanol and sitosterol, respectively, after the GLOX treatment in agreement with the results observed in pulps. These results show that peroxidation reactions could mediate the co-oxidation of these lipids. Similar findings were reported in the removal of alkanes and fatty alcohols from flax pulps with laccase in the presence of HBT as mediator (Molina et al., 2008). The fact that lipid radicals generated from peroxidation of unsaturated lipids such as linoleic acid participate in the oxidation of the less reactive lipophilic compounds suggests that GLOX can be used to remove lipophilic extractives from pulps where linoleic acid is present.

\subsection{Pulp properties after lipoxygenase treatment}

In addition to the enzymatic removal of lipophilic extractives from pulps, the effect of the lipoxygenase treatment on some selected properties of the pulps were assessed, including kappa number (a rough estimation of the lignin content in pulp), brightness and intrinsic viscosity (an estimation of cellulose integrity). Table 3 shows the results for eucalypt pulp. Pulps with lower kappa number (1.2 points decrease) and increased brightness (2.6 and 3.4 points increase, in the absence and presence of linoleic acid, respectively) were obtained after treatment with GLOX and subsequent peroxide stage. No improvement of pulp brightness (and only a decrease of 0.7-0.8 points in kappa number) was observed when the enzymatic treatment was not followed by a hydrogen peroxide stage, revealing the need of an alkaline peroxide stage after the lipoxygenase treatment to improve pulp properties. Pulp viscosity was maintained after the enzymatic treatment although decreased after the peroxide stage. 
Table 3

Properties of eucalypt pulp treated with the G. graminis lipoxygenase (GLOX) in the absence and presence of linoleic acid (LA) before and after a $\mathrm{H}_{2} \mathrm{O}_{2}$ stage (P), and control without enzyme.

\begin{tabular}{|c|c|c|c|c|c|c|}
\hline & \multicolumn{2}{|c|}{ Control } & \multicolumn{2}{|l|}{ GLOX } & \multicolumn{2}{|c|}{ GLOX/LA } \\
\hline & Initial & $\mathrm{P}$ & Initial & $\mathrm{P}$ & Initial & $\mathrm{P}$ \\
\hline Kappa number & 13.5 & 10.7 & 12.8 & 9.5 & 12.9 & 9.5 \\
\hline Brightness (\% ISO) & 44.0 & 55.9 & 43.8 & 58.5 & 43.9 & 59.3 \\
\hline Intrinsic viscosity $(\mathrm{mL} / \mathrm{g})$ & 1140 & 925 & 1148 & 800 & 1143 & 767 \\
\hline
\end{tabular}

Table 4

Properties of flax pulp treated with the G. graminis lipoxygenase (GLOX) in the absence and presence of linoleic acid (LA) before and after a $\mathrm{H}_{2} \mathrm{O}_{2}$ stage (P), and control without enzyme.

\begin{tabular}{|c|c|c|c|c|c|c|}
\hline & \multicolumn{2}{|c|}{ Control } & \multicolumn{2}{|l|}{ GLOX } & \multicolumn{2}{|c|}{ GLOX/LA } \\
\hline & Initial & $\mathrm{P}$ & Initial & $\mathrm{P}$ & Initial & $\mathrm{P}$ \\
\hline Kappa number & 9.3 & 5.1 & 9.1 & 5.2 & 8.6 & 5.5 \\
\hline Brightness (\% ISO) & 35.1 & 61.2 & 35.1 & 62 & 35.3 & 62.4 \\
\hline Intrinsic viscosity $(\mathrm{mL} / \mathrm{g})$ & 787 & 535 & 762 & 648 & 779 & 602 \\
\hline
\end{tabular}

Although higher increases in ISO brightness and decreases in kappa number than those shown here (Table 3 ) have been reported for some laccase treatments in the presence of redox mediators (especially synthetic mediators such as HBT or violuric acid), it should be mentioned that large differences in these values are observed in the different studies that are highly dependent on the operating conditions (Gutiérrez et al., 2006a, 2007; Ibarra et al., 2006; Moldes et al., 2008).

In the case of flax pulp (Table 4), an increase of 0.8 and 1.2 points of ISO brightness was achieved after the enzymatic treatment followed by the hydrogen peroxide stage, in the absence and presence of linoleic acid, respectively (no increase of brightness was observed before the hydrogen peroxide stage). No significant decrease of kappa number (lower than 1 point) was observed after the enzymatic treatment of flax pulp (before the peroxide stage). After peroxide, the kappa number did not decrease and the viscosity increased. Higher enhancement in ISO brightness and decrease in kappa number have been attained by laccase treatment of flax pulp in the presence of mediators (Camarero et al., 2004; Fillat et al., 2010).

The better delignification values observed in the GLOX treatment of eucalypt pulp compared with those of flax pulp treatment can be related with the different composition and structure of lignin in these two types of pulp. The lignin from eucalypt pulp is characterized by a high abundance of syringyl units (Ibarra et al., 2005) and, therefore, it is easier to delignify than lignin from flax pulp that is mainly constituted by guaiacyl units (Camarero et al., 2004).

\section{Conclusions}

The potential of GLOX to remove lipophilic extractives from eucalypt and flax pulps was studied. A high removal of esterified and glycosylated sterols was achieved by the GLOX treatment of eucalypt pulps, while only a slight decrease of free sterols was observed. Higher decreases of lipophilic extractives in flax pulp were produced, including free sterols. In addition, the GLOX treatment produced a significant increase of brightness and decrease of kappa number in eucalypt pulp, although only limited brightness enhancement in flax pulp. Given the significant alkaline activity of lipoxygenases, it is suggested that these may have potential use in brown stock treatment as a means for reducing down- stream deposition problems as well as reducing the amount of chemicals in the subsequent bleaching stages.

\section{Acknowledgements}

This study has been supported by the Spanish projects BIO2007-28719-E and AGL2008-00709 and the EU project BIORENEW (NMP2-CT-2006-026456). Novozymes (Bagsvaerd, Denmark) is acknowledged for GLOX supply and ENCE (Pontevedra, Spain) and CELESA (Tortosa, Spain) for eucalypt and flax paper pulp samples, respectively. J. Romero (ENCE) and T. Vidal (UPC, Barcelona, Spain) are acknowledged for pulp properties determination.

\section{References}

Back, E.L., Allen, L.H., 2000. Pitch control, wood resin and deresination. TAPPI Press, Atlanta.

Barfoed, M., 2000. Methods of hydrolyzing cholesterol esters by using a Pseudomonas fragi cholesterol esterase. Patent (International) W09423052.

Borch, K., Franks, N., Lund, H., Xu, H., Luo, J., 2003. Oxidizing enzymes in the manufacturing of paper materials. Patent (USA) US 2003-0124710 A1.

Bourbonnais, R., Paice, M.G., 1990. Oxidation of non-phenolic substrates. An expanded role for laccase in lignin biodegradation. FEBS Lett. 267, 99-102.

Brash, A.R., 1999. Lipoxygenases: occurrence, functions, catalysis, and acquisition of substrate. J. Biol. Chem. 274, 23679-23682.

Buchert, J., Mustranta, A., Tamminen, T., Spetz, P., Holmbom, B., 2002. Modification of spruce lignans with Trametes hirsuta laccase. Holzforschung 56, 579-584.

Call, H.-P., 1994. Verfahren zur Veränderung, Abbau oder Bleichen von Lignin, ligninhaltigen Materialien oder ähnlichen Stoffen. Patent (International) WO 94/29510.

Camarero, S., García, O., Vidal, T., Colom, J., del Río, J.C., Gutiérrez, A., Gras, J.M., Monje, R., Martínez, M.J., Martínez, A.T., 2004. Efficient bleaching of non-wood high-quality paper pulp using laccase-mediator system. Enzyme Microb. Technol. 35, 113-120.

Fillat, A., Colom, J.F., Vidal, T., 2010. A new approach to the biobleaching of flax pulp with laccase using natural mediators. Bioresour. Technol. 101, 4104-4110.

Fujita, Y., Awaji, H., Taneda, H., Matsukura, M., Hata, K., Shimoto, H., Sharyo, M., Sakaguchi, H., Gibson, K., 1992. Recent advances in enzymic pitch control. Tappi J. 75 (4), 117-122.

Gutiérrez, A., del Río, J.C., 2001. Gas chromatography-mass spectrometry demonstration of steryl glycosides in eucalypt wood, kraft pulp and process liquids. Rapid Commun. Mass Spectrom. 15, 2515-2520.

Gutiérrez, A., del Río, J.C., 2005. Chemical characterization of pitch deposits produced in the manufacturing of high-quality paper pulps from hemp fibers. Bioresour. Technol. 96, 1445-1450.

Gutiérrez, A., del Río, J.C., González-Vila, F.J., Martín, F., 1998. Analysis of lipophilic extractives from wood and pitch deposits by solid-phase extraction and gas chromatography. J. Chromatogr. 823, 449-455.

Gutiérrez, A., del Río, J.C., González-Vila, F.J., Martín, F., 1999. Chemical composition of lipophilic extractives from Eucalyptus globulus Labill. Wood. Holzforschung 53, 481-486.

Gutiérrez, A., del Río, J.C., Martínez, M.J., Martínez, A.T., 2001a. The biotechnological control of pitch in paper pulp manufacturing. Trends Biotechnol. 19, 340-348.

Gutiérrez, A., Romero, J., del Río, J.C., 2001b. Lipophilic extractives from Eucalyptus globulus pulp during kraft cooking followed by TCF and ECF bleaching. Holzforschung 55, 260-264

Gutiérrez, A., del Río, J.C., Ibarra, D., Rencoret, J., Romero, J., Speranza, M., Camarero, S., Martínez, M.J., Martínez, A.T., 2006a. Enzymatic removal of free and conjugated sterols forming pitch deposits in environmentally sound bleaching of eucalypt paper pulp. Environ. Sci. Technol. 40, 3416-3422.

Gutiérrez, A, del Río, J.C. Rencoret, J. Ibarra, D., Martínez, A.T. 2006b. Main lipophilic extractives in different paper pulp types can be removed using the laccase-mediator system. Appl. Microbiol. Biotechnol. 72, 845-851.

Gutiérrez, A., Rencoret, J., Ibarra, D., Molina, S., Camarero, S., Romero, J., del Río, J.C. Martínez, A.T., 2007. Removal of lipophilic extractives from paper pulp by laccase and lignin-derived phenols as natural mediators. Environ. Sci. Technol. 41, 4124-4129.

Gutiérrez, A., del Río, J.C., Martínez, A.T., 2009. Microbial and enzymatic control of pitch in the pulp and paper industry. Appl. Microbiol. Biotechnol. 82, 10051018

Hamberg, M., Su, C., Oliw, E., 1998. Manganese lipoxygenase - Discovery of a bisallylic hydroperoxide as product and intermediate in a lipoxygenase reaction. J. Biol. Chem. 273, 13080-13088.

Ibarra, D., del Río, J.C., Gutiérrez, A., Rodríguez, I.M., Romero, J., Martínez, M.J., Martínez, A.T., 2005. Chemical characterization of residual lignins from eucalypt paper pulps. J. Anal. Appl. Pyrolysis 74, 116-122.

Ibarra, D., Romero, J., Martínez, M.J., Martínez, A.T., Camarero, S., 2006. Exploring the enzymatic parameters for optimal delignification of eucalypt pulp by laccasemediator. Enzyme Microb. Technol. 39, 1319-1327.

International Organisation for Standardization Documentation, Information (ISO) 2003. ISO Standards Collection on CD-ROM. Paper board and pulps, ISO, Geneva. 
Kapich, A.N., Korneichik, T.V., Hatakka, A., Hammel, K.E., 2010. Oxidizability of unsaturated fatty acids and of a non-phenolic lignin structure in the manganese peroxidase-dependent lipid peroxidation system. Enzyme Microb. Technol. 46 136-140.

Marques, G., del Rio, J.C., Gutiérrez, A., 2010. Lipophilic extractives from severa nonwoody lignocellulosic crops (flax, hemp, sisal, abaca) and their fate during alkaline pulping and TCF/ECF bleaching. Bioresour. Technol. 101, 260-267.

Moldes, D., Diaz, M., Tzanov, T., Vidal, T., 2008. Comparative study of the efficiency of synthetic and natural mediators in laccase-assisted bleaching of eucalyptus kraft pulp. Bioresour. Technol. 99, 7959-7965.

Molina, S., Rencoret, J., del Río, J.C., Lomascolo, A., Record, E., Martínez, A.T., Gutiérrez, A., 2008. Oxidative degradation of model lipids representative for main paper pulp lipophilic extractives by the laccase-mediator system. Appl. Microbiol. Biotechnol. 80, 211-222.

Morrison, W.H.I., Akin, D.E., 2001. Chemical composition of components comprising bast tissue in flax. J. Agric. Food Chem. 49, 2333-2338.
Prigge, S.T., Boyington, J.C., Faig, M., Doctor, K.S., Gaffney, B.J., Amzel, L.M., 1997. Structure and mechanism of lipoxygenases. Biochemie 79, 629-636.

Speranza, M., Martínez, M.J., Gutiérrez, A., del Río, J.C., Martínez, A.T., 2002. Wood and pulp localization of sterols involved in pitch deposition using filipin fluorescent staining. J. Pulp Paper Sci. 28, 292-297.

Su, C., Oliw, E.H., 1998. Manganese lipoxygenase - Purification and characterization. J. Biol. Chem. 273, 13072-13079.

Valls, C., Molina, S., Vidal, T., del Río, J.C., Colom, J., Martínez, A.T., Gutiérrez, A., Roncero, M.B., 2009. Influence of operation conditions on laccase-mediator removal of sterols from eucalypt pulp. Process Biochem. 44, 1032-1038.

Zhang, X., Renaud, S., Paice, M., 2005. The potential of laccase to remove extractives present in pulp and white water from TMP newsprint mills. J. Pulp Paper Sci. 31, 175-180.

Zhang, X., Nguyen, D., Paice, M.G., Tsang, A., Renaud, S., 2007. Degradation of wood extractives in thermo-mechanical pulp by soybean lipoxygenase. Enzyme Microb. Technol. 40, 866-873. 